\title{
A PERICULOSIDADE CRIMINAL
}

\author{
Ernani Cabral de Loyola Fagundes \\ Professor da Faculdade de Direito e presidente \\ do Instituto dos Advogados de Goiás.
}

O estudo, a análise, o exame da periculosidade criminal é problema de transcendental importância para o Direito Penal.

Se o indivíduo demonstra-se perigoso à ordem social, deve ser segregado do convívio de seus concidadãos, porque sua conduta torna-se perniciosa e funesta à coletividade; êle já é, sem dúvida, um criminoso em potência.

0 ideal seria que a polícia preventiva pudesse, não sòmente vigiar, mas sobretudo internar, aqueles que, pelo seu procedimento incorreto, apresentassem índices de temibilidade. Mas, como bem pondera Cuellon Calón, "por mais perigoso que pareça ser um indivíduo, por mais imoral que seja sua conduta, enquanto não cometa infração da lei penal, não se pode submetê-lo a qualquer medida de segurança", ressalvado apenas 0 disposto nos arts. 549 a 555 do C. P. P. brasileiro.

0 direito à liberdade é sagrado e ninguém pode estar sujeito a suspeitas de crime que ainda não cometeu, mesmo porque o fronteiriço das penitenciárias, pode ser que jamais nelas penetre, por circunstâncias ou por motivos diversos, assim como propenso à tuberculose pode deixar de adquirir o bacilo de Koch.

Mas se alguém tornar-se delinquente, é de grande interêsse social que seja determinado o grau de sua periculosidade, porque o crime cometido pode estar aquem dessa periculosida- 
de, e é preciso que o criminoso seja tratado na penitenciária, criteriosamente, de modo a que venha a se readaptar ao convívio social, funcionando a pena como um processo curativo do delinquente.

É verdade que, na prática, estas idéias acadêmicas, dificilmente, são postas em execução. 0 espírito de rotina, que é sempre retrógrado, reage contra as inovações. A ciência penal está sempre mais avançada do que a realidade objetiva. Mas nem por isto ela deve parar em suas observações, em seus estudos, nem os idealistas desanimarem em seus sonhos de progresso ou de aperfeiçoamento das instituições humanas. As conquistas da civilização nascem no cérebro dos precursores, dos cientistas, dos filósofos, daquêles que são possuidores de sentimentos nobres ou superiores, visando o bem comum. A boa doutrina vaj convencendo, e a sociedade, vagarosamente, progredindo. A lei - que podemos chamar de divina - é da evolução constante, em todos os ramos da atividade, embora a perfeição jamais possa ser atingida em nosso plano. Mas natura non facit saltus. As transformações dos institutos jurídicos são lentas, pois sujeitas a várias injunções, porém a verdade é que a doutrina e a prática do direito têm melhorado sempre.

Relativamente à tese que abordamos, os mestres da ciência penalógica hão compreendido a conveniência e a necessidade do estudo da periculosidade do delinquente, afim de que possam ser tiradas conclusões de ordem prática, de carater proveitoso para a sociedade, que precisa não só se prevenir contra o delito, mas estabelecer medidas adequadas de punição ou de segurança.

O próprio Código Penal Brasileiro recomenda, em seu art. 42, que, para a fixação da pena, o juiz atenda aos antecedentes e à personalidade do agente, e também à intensidade do dolo. Portanto, a personalidade do agente, seus antecedentes e a intensidade do dolo - que devem ser cuidadosamente examinados pelo juiz, antes de proferir a sentença - são índices legais e verdadeiros - embora não absolutos - da perversidade do delinquente ou de sua periculosidade criminal. 
Como bem lembra o prof. Roberto Lyra, "a periculosidade condiciona as medidas de segurança (arts. 76,II e 77) e influi na qualidade e na quantidade das penas (art. 42), como eixo de tôda a justiça, baseada na realidade humana, individual e social".

0 art. 77 do Código Penal prescreve:

"Quando a periculosidade não é presumida por lei, deve ser reconhecido perigoso o indivíduo, se a sua personalidade e antecedentes, bem como os motivos e circunstâncias do crime autorizem a suposição de que venha ou torne a delinquir".

É claro que um criminoso, que tem evidente propensão para a reincidência, genérica ou específica, merece ser tratado com mais cuidado ou com mais precaução pelo Estado, porque é uma criatura perversa, capaz de tornar extensos e múltiplos os danos aos direitos individuais ou coletivos.

O Supremo Tribunal Federal decidiu a propósito, no habeas corpus N. ${ }^{\circ} 28.427$, de 30 de junho de 1934, tendo como relator o Ministro Goulart de Oliveira:

"A lei concede ao juiz o poder discricionário para proceder a individualização da pena, mas para proceder a ela só em função de seu escôpo essencial, que é o de retribuir o mal com o mal igual, entendida essa igualdade no sentido da proporcionalidade.

"Ao poder discricionário do juiz corresponde uma obrigação manifesta: a de provar, cumpridamente, ou pelo menos, a de mencionar, claramente, a fundamentação na qual baseara a graduação operada".

Data venia, a pena não é apenas a retribuição do mal com o mal, porque a sociedade não deve ter idéia de vingança, já que o criminoso é uma pessoa desajustada, um inadaptado ao meio 
social, como diz Vaccaro, e a pena deve ser o processo humano de sua correção.

Consoante declara Roberto Lyra, "o crime vale como sintoma da personalidade do criminoso, e não como entidade absoluta. A defesa social tem finalidade direta - a readaptação empenhando-se, especificadamente, pela eliminação da causa do crime. Impõe-se, assim, a individualização, considerando-se o conteúdo do crime e a personalidade do delinquente para determinar o tratamento mais adequado. 0 objetivo da defesa social não é o fato, mas o seu autor, ou melhor, o homem".

Carnelutti chega a pugnar que o criminoso seja tratado com caridade, isto é, com amor. Realmente, "só o amor constroi para a eternidade" e a evolução da ciência penal deve visar o bem do delinquente e não sua desgraça, porque êle também é um ser humano que, embora tenha errado e mesmo sendo necesário afastá-lo da comunidade, mais por um problema de higiene social ou de auto-defesa do Estado, nem por isto deixa de ser um cidadão ou uma pessoa humana, que também possui seus direitos e a quem o Estado não deve oprimir. A função da pena é de regenerar o delinquente e não de o tornar infeliz ou revoltado contra a sociedade.

Em virtude dessas mesmas considerações, somos contrários à pena de morte, pois o direito à vida, que é básico ou fundamental, transcende à fôrça coerciva do Estado. Ninguém tem o direito de tirar aquilo que não pode dar e verificam-se êrros de justiça, que em tais casos seriam irreparáveis. Além disto, o homem, por mais terrível ou perigoso que pareça, pode ainda melhorar ou regenerar-se. A história do Direito Criminal está cheia desses exemplos. Mas se o delinquente é um tarado, um incurável, ainda assim a sociedade deve condoer-se dêle, porque, finalmente, não teve culpa de nascer dessa maneira, mas foram os fatores endógenos ou nosológicos de seus ancestrais - para cuja amplitude o meio ambiente, com suas imperfeições, também contribuiu - que determinaram seu desiquilíbrio psícosomático. É mais humano que pessoas assim sejam, por medi- 
da de segurança, internadas em um nosocômio judiciário, e não mortas por ordem da justiça que, a nosso ver, não tem a faculdade de privar alguém de um direito, que transcede à órbita da tutela do Estado, o qual jamais se deve transformar em algoz ou carrasco, mas em um controlador prudente e criterioso das mazelas sociais, para as quais êle também contribui com suas deficiências, porque o Estado perfeito é uma utopia.

A função do Estado é manter o equilíbrio nas relações jurídicas sem massacrar qualquer direito; todos êles são dignos de sua proteção, mesmo em se tratando das pessoas de degenerados, pois êstes não têm culpa de haverem nascido assim, à sombra do Estado, que lhes deverá dar assistência e amparo, mas nunca a morte!

Há juristas, como Jorge Severiano, que estranham a expressão "idensidade do dolo", usada no art. 42 de nosso Código Penal. Não há vontade mais extensa ou menos extensa, quando ela já se manifestou integralmente no delito. Quando o agente diz "eu quero" e praticou o crime, assumiu o risco do resultado.

Mas a matéria da volição, que é vasta e tem sinuosidades temperamentais, não pode ser julgada com conceitos tão curtos e tão estreitos, como se fôsse possível jungir a conclusões dogmáticas o processo subjetivo do dolo ou a intensidade da vibração da alma humana.

Mais razão tem Bento de Faria, quando ensina:

"O dolo, de modo geral, caracteriza o delito intencional, isto é, a ação contrária à lei penal, praticada ciente e voluntàriamente.

"Supõe sempre no delinquente o pleno conhecimento do mal e a direta intenção de praticálo. É o dolo ordinário ou comum, expressivo da vontade, nos elementos que a integram; na energia e na maneira porque a impulsiona pode apresentar modalidades que traduzem aspectos específicos da sua maior gra- 
vidade ou que reflitam, em comparação, a menor temibilidade do agente".

O Ministro Orozimbo Nonato, então deduz:

"E como as circunstâncias a que alude o art. 42 não se baralham àquelas que sempre agravam ou diminuem a pena (arts. 44 e 48) o que se conclui é que, além das fixações da lei, o juizo deve analisar o caso com critério próprio e seguro, reconhecendo fatos e circunstâncias múltiplas, impossíveis de mencionados, em sua imensa variedade, pelo mais prevenido dos legisladores".

A questão da fixação da pena, levando-se em conta a periculosidade criminal, é tão importante, que os tribunais têm decidido:

"Nula, por omissão de formalidade essencial (Cod. Proc. Penal, art. 567, n. ${ }^{\circ} 4$, combinado com o art. 387) é a sentença que não deixa expressão como e porque aplicou aos réus a pena.

"Não basta que o Juizo, entendendo provados o crime e a responsabilidade dos acusados, a êstes aplique , arbitràriamente, certas doses de pena entre os limites estatuidos nos dispositivos do Cód. Penal, em que incorreram ditos acusados; é imprescindível que o julgador deixe claro como e porque chegou a fixação ou dosagem das penas impostas na sentença; não tendo êle o arbítrio absoluto na escolha da pena, quando a lei estabelecer duas alternadamente, não tem ainda relativamente à fixação do quantum de uma ou de ambas, cumprindo-lhe, ao contrário, deixar clara e discriminadamente expressos quais os motivos que o levaram ao resultado final, isto é, o que constitui a individualização da pena, com o emprêgo dos meios e critérios indicados nos arts. 42, 43, 48 e 50 do Cód. Penal". 
Foi o que julgou a $2^{\text {a }}$ Câmara do Tribunal de Justiça do Distrito Federal, na apelação criminal n. ${ }^{\circ} 5.929$, tendo como relator o sr. desemb. Toscano Espínola.

A perícia psiquiátrica é aconselhável, afim de que seja determinada a periculosidade criminal.

0 prof. dr. A. C. Pacheco e Silva, catedrático de clínica psiquiátrica da Faculdade de Medicina da Universidade de São Paulo, proferiu importante conferência, de cujo estudo nos serviremos, de agora em diante, para ilustração dêste estudo.

Diz o festejado mestre que o perito judicial deve, não apenas se pronunciar sôbre as condições psíquicas de determinada pessoa em um momento dado, "mas também prever a sua potencialidade criminal, capaz de se revelar, cêdo ou tarde, por reações antissociais".

Em linguagem médica, diriamos: exige-se dêle, não apenas a fixação de um diagnóstico, como cumpre precisar-se o prognóstico.

Comentando os novos rumos da Penalogia, Osval Loudet diz, por isso, mui acertadamente: "A aplicação integral da doutrina do estado perigoso nos leva a uma consequência prática análoga à aplicação da medicina preventiva. Por que esperar 0 aparecimento de um sistema objetivo para depois aplicar sanções, quando a verdadeira defesa consiste, precisamente, em tomar medidas acauteladoras e tutelares, antes de se consumar a reação antissocial e quando o estado perigoso já é perceptível?

"Foi mercê da evolução das ciências biológicas, dos progressos da psiquiatria e dos novos conceitos admitidos pelos codificadores, que a defesa social assumiu um carater verdadeiramente preventivo, profilático, de grande alcance na defesa da sociedade contra os elementos capazes de praticar reações perigosas e comprometer a saúde ou a vida dos seus semelhantes.

"A nova orientação representa uma vitória das ciências positivas, que após anos de incessante luta logrou convencer os 
legisladores da necessidade da adoção de medidas acauteladoras do interêsse social, fundadas em princípios mais humanos, mais práticos e mais eficientes, Mas, de outra parte, assumem os psiquiátras encarregados da execução das perícias da periculosidade criminal redobrada responsabilidade, que vai dêles exigir profundos conhecimentos, ao par de grande critério na elaboração das conclusões.

"O juiz encarregado de proferir a sentença, por seu turno, deverá também dispor de largo preparo especializado, afim-de poder apreciar devidamente o laudo pericial, na aplicação das medidas de segurança.

"A tarefa de ambos, perito e juiz, não é fácil. Não há um critério definitivo que permita se estabelecerem regras precisas e imutáveis. Não se descobriu ainda nem o frenômetro para se sondar o estado psíquico de um doente e muito menos o perigômetro para a verificação do grau de periculosidade de determinado indivíduo. Cada caso é um caso concreto. Impõe-se o estudo detido de uma série de fatores e de circunstâncias, para nos aproximarmos do ideal, que seria preservar a sociedade dos elementos capazes de provocar reações que atentem contra a sua segurança e, ao mesmo tempo, atender, na medida do possível, à liberdade individual".

Mas - perguntamos nós - o que vem a ser exatamente, a periculosidade criminal?

Grispini - que faz distinção entre a periculosidade psíquica e a jurídica, define a periculosidade criminal como "a muito relevante capacidade de uma pessoa a cometer um delito". Ferri dá ao fenômeno o nome de periculosidade social.

Arturo Rocco diz simplesmente: "a temibilidade de um indivíduo é a consequência de sua periculosidade".

Quanto mais perigoso fôr um homem, mais temível à harmonia social; sua potencialidade criminal será então presumida; êle é um ser a exigir que a justiça pública se ponha em estado de alerta. 
Osval Laudet, no $10^{\circ}$ Congresso Latino-Americano de Criminologia, propôs a seguinte definição:

" $O$ indivíduo em estado perigoso é aquêle que, por condições psíquicas, que constituem ou não entidades nosológicas ou simples desequilíbrios permanentes ou transitórios, por hábitos adquiridos ou impostos na vida coletiva, ou por outras causas simples ou combinadas, se encontra na possibilidade transitória ou permanente de ter reações antissociais imediatas".

Já Pacheco e Silva entende que essa definição não é clara e precisa, mas vulnerável, como tôdas as demais, "conquanto a justifique pelo fato de encerrar um diagnóstico e um prognóstico do estado perigoso".

Embora reconhecendo - como já faziam os romanos que omnia definitio periculosa est, nós queremos dar o conceito ou a definição da matéria, entendendo que PERICULOSIDADE CRIMINAL É O GRAU DE PERVERSIDADE DO INDIVÍDUO, CAPAZ DE ECLODIR NA PRÁTICA OU NA REINCIDÊNCIA DO DELITO, DESDE QUE HAJAM MOTIVOS DETERMINANTES OU AMBIENTE PROPÍCIO PARA SUA CONDUTA ANTISSOCIAL.

Não nos referimos ao estado nosológico, aos desequilíbrios permanentes ou transitórios, porque êstes estão implícitos na periculosidade criminal, dependendo da hipótese sub-judice a observar-se. Os fatores podem ser múltiplos, em sua etiologia, e a periculosidade criminal adquirida ainda por defeitos de educação, por simples revolta contra a sociedade ou por hipertrofia do egoismo, mas, seja qual fôr a causa, seu índice de manifestação será aquilatado pela perversidade ou temibilidade do delinquente.

Roberto Lyra acentua que, "em última análise, várias correntes médicas, jurídicas e sociológicas concordam em que o estado perigoso consiste na probalidade do indivíduo cometer ou tornar a cometer crime. 
"De qualquer forma, a periculosidade está menos no indivíduo do que no meio, donde partem os motivos, as ocasióes, os elementos para delinquir; por isto mesmo, fala-se no estado perigoso social.

"O crime é um fenômeno social e a própria anormalidade provem das condições de vida.

Jimenez de Asúa considera como elementos capazes de caracterizar a periculosidade criminal os seguintes:

1. ${ }^{\circ}$ A personalidade do homem sob o seu tríplice aspecto antropológico, psíquico e moral.

$\left.2 .^{\circ}\right)$ A vida anterior ao delito.

$3 .^{\circ}$ ) A conduta do agente posterior ao delito.

$\left.4 .^{\circ}\right)$ A qualidade dos motivos.

$\left.5 .^{\circ}\right) \quad O$ delito cometido.

0 crime praticado é sempre uma expressão da periculosidade e a manifestação do desajustamento social do delinquente. Às vezes manifesta-se com tanto requinte de perversidade, que já define o grau da temibilidade. Mas nem sempre, conforme fizemos sentir, demonstra com clareza a índole do criminoso. Todavia, já é um índice de pesquisa, cabendo ao perito, ao juiz e às penitenciárias completarem o estudo da individualidade do delinquente, à luz de outras investigações e observações.

"Ao comentar as medidas de segurança adotadas no sistema do Cód. Penal italiano de 1930, Humberto del Pozzo esclarece: "Ao julgar a periculosidade do caso em questão, o juiz deve ter em conta a gravidade do delito, segundo - 1) A natureza, os meios, o tempo, o lugar e qualquer outra modalidade de ação; 2) A gravidade do dano ou o perigo a que ficou sujeita a pessoa ofendida pelo delito; 3 ) A intensidade do dolo e o grau da culpa".

Aquêle notável professor de Turim ensina:

"Quanto aos critérios concretos, legislativos, determinadores dêste último motivo, a periculosida- 
de social (na qual, òbviamente está a importância maior do artigo da lei) o direito penal italiano autoriza, totalmente, as seguintes conclusões que julgo - diz Humberto del Pozzo - aplicáveis a tôdas as legislações, como modêlo quase insuperável:

a) A periculosidade não é um critério abstrato, mas se a pode determinar objetivamente, por sintomas concretos, fixados pela lei penal e obrigatòriamente impostos ao juiz no exercício de seu valor objetivo.

b) 0 critério fundamental para o juizo da periculosidade, quer dizer, da atitude do delinquente em perseverar no delito, está implícito na mesma personalidade do delinquente.

c) O problema da periculosidade é, em suma, um problema da personalidade, que só se resolve com uma indagação de natureza psicológica e antropológica sôbre a natureza e sôbre a individualidade do delinquente."

0 prof. Pacheco e Silva faz uma sistematização que considera mais lógica do que a do Código italiano, dividindo-a em três partes:

$\left.10^{\circ}\right)$ Indagação específica, quer dizer, indagação relativa à ação criminosa, quanto ao sintoma ou ao índice da personalidade do culpado.

$\left.2 .^{\circ}\right)$ Indagação sôbre os fatores endógenos, isto é, indagação antropológica relativa à personalidade física e psíquica, natureza, carater etc. do réu.

$\left.3 .^{\circ}\right)$ Indagação sôbre os fatores exógenos: indagação sociológica relativas aos fatôres externos, do ambiente, individuais, familiares e sociais".

Ainda Osvaldo Loudet, no excelente relatório que apresen- 
tou ao Primeiro Congresso Latino-Americano de Criminologia, determinou os índices "médico-patológicos" e legais da periculosidade, da seguinte maneira: - a) Indices médico-patológi$\cos ; \mathrm{b})$ Indices sociais; c) Indices legais. Dêstes três índices, ensina Loudet, os dois primeiros são substanciais, porque traduzem a personalidade do indivíduo e suas reações em determinado meio social, se bem que o último tenha um valor sintomático variável. 0 índice essencial é o médico psicológico, mais grave, mais permanente, menos mutável. 0 índice social é menos grave, mais transtitório, menos susceptível de modificações. Os índices legais podem ser, ou não, os reflexos dos primeiros. Isto quer dizer que para se formar um juizo da personalidade do agente deve-se atender a sua índole e, em segundo, o ambiente social, onde êle se nutre e se move, e por último, as figuras delituosas como expressões jurídicas.

"O insigne psiquiatra e criminalista argentino, portanto, entende como índice médico-psicológico da periculosidade, as entidades psíquicas ou as simples desarmonias da própria natureza, vinculadas, ou não, à perturbações somáticas que, em determinadas ou indeterminadas circunstâncias, permitem prognosticar uma reação antissocial num dado indivíduo".

Data venia, discordamos do ilustre médico argentino, quando êle dá sempre a predominância aos fatores antropológicos na etiologia da periculosidade criminal. Reconhecemos que êstes são mesmo os mais comuns. Todavia, há casos em que os fatores mesológicos são decisivos na gênese da periculosidade, tudo dependendo do estudo de cada caso em particular. Às vezes o criminoso é um devasso, um debochado - permitindonos o galicismo - que perverteu seu senso moral pelo excesso de dinheiro, que lhe foi proporcionado na mocidade, por pais tolerantes ou excessivamente condescendentes para com as orgias do filhinho. Criatura que abusou da riqueza, entendendo que ela lhe serve tão sòmente para satisfação dos gozos pessoais, entrando em convivência com outros libertinos, acabou êste homem por se transformar em um degenerado com a abolia do senso moral, em face da educação cômoda e deletéria que teve 
Vemos aí a influência decisiva dos fatores sociais na etiologia da criminalidade ou dêste caso típico de periculosidade criminal, que ora examinamos. É certo que os fatores nosológicos são os mais comuns. Entretanto, não são os únicos e nem sempre se deve reconhecer sua predominância, dependendo do exame pessoal ou individual do delinquente. Cada caso, portanto, deve merecer um estudo acurado dos encarregados de zelar pela paz social, sempre ameaçada por aquêles que, per defeitos de educação ou por taras congênitas ou hereditárias, têm propensão para o terreno escabroso do crime.

Renieri, reunindo os critérios de Feuerbach, Mittermayer, Garofalo, Liszt, Storch, Rocco, Florian etc., incluiu na fórmula da periculosidade os seguintes requisitos: a) Consumação ou tentativa do crime; b) Capacidade para delinquir; c) Tendência a reincidir; d) Temibilidade; e) Probabilidade de violação do direito; f) Probabilidade da prática de novo crime; g) Natureza intelectual especial, que impeça os efeitos da ameaça e da execução da pena ordinária; h) Probabilidade de um indivíduo cometer crimes graves.

Roberto Lyra ensina com a clareza e a profundeza que lhe são próprias :

"A periculosidade é concebida como estado momentâneo e como estado duradouro, distinguindo-se em genética e específica; em normal e anormal; em intensiva e extensiva; em iminente e não iminente. Os autores ainda consideram diversamente a periculosidade em relação as diferentes classes de delinquentes, de crime e de elementos dêstes. A periculosidade é criminal considerada subjetivamente e social, consideradada objetivamente, em relação ao temor que cria entre os co-associados. A primeira ocorre sempre post delictum, a segunda pode, também verificar-se ante delictum.

"A periculosidade pré-delitual não interessa à justiça penal, mas à política social. 0 médico, o ju- 
rista, o pedagogo não abrangem os desdobramentos do fenômeno, ligado, essencialmente, à organização social.

"Avulta, nêsse tumulto doutrinário, o comando de Ferri, que indicava duas normas para disciplinar em concreto a periculosidade: a qualidade mais ou menos anti-social do ato e do agente. A primeira deriva de dois elementos: o do direito violado e dos motivos determinantes; a segunda liga-se às diversas categorias de delinquentes, segundo os dados da antropologia e da psicologia criminal. No entender de Ferri, a periculosidade deve ser estudada segundo o grau, a provável duração e a tendência, resultando, na ordem ascendente de importância, da gravidade do crime, dos motivos determinantes e da personalidade.

"Grispigni e Asúa referiram-se ao exame da vida anterior e do comportamento depois do crime, que figura no da personalidade, conforme a concepção de Ferri.

"Segundo Manzini, ao concretizar a pena, o juiz não deve considerar a periculosidade, mas a criminosidade atual, porque trata de reprimir e não de prevenir. Na maioria das vezes, criminosidade e periculosidade são equivalentes, porém tal aquivalência - conclui - não pode ser admitida sempre,

"Esqueceu Manzini o fim da prevenção especial que êle mesmo reconhece na pena. Repressão e prevenção são momentos inseparáveis da mesma defesa social. No entanto, a pena dirige-se sempre ao futuro. 0 próprio Rocco, tão sóbrio em relação à periculosidade, nega que esta possa influir na cominação, mas aceita na aplicação".

É de interesse que acentuemos o valor da prática ou do exa- 
me psiquiátrico criminal para determinar a periculosidade ou a temibilidade do delinquente.

Os estudiosos frisam que, "quando se trata de crimes praticados por agentes reconhecidamente alienados, que apresentam alucinações, idéias delirantes ou outros sintomas evidentes de doença mental, quase nunca se registram desentendimentos".

"O mesmo não ocorre, porém, quando se trata da personalidade dos chamados degenerados, dos anormais, dos perversos, dos amorais, das personalidades psicopáticas, em uma palavra, dos hoje denominados fronteiriços".

Toulouse, com sua vasta experiência e com sua reconhecida cultura, comenta:

"O prestígio da ciência, os progressos da psiquitria e da criminologia não são, por enquanto, de moldes a dirimir as dúvidas suscitadas pelos atos dos grandes criminosos que se comportam, no interrogatório, como homens lúcidos, mas cujos antecedentes e circunstâncias em que delinquiram, levantam a suspeita de sua morbidez".

Mas, pergunta o prof. Pacheco e Silva, "porque razão a perícia não resolve, definitivamente, semelhantes casos? - Quem responde é ainda Toulouse:

“É por uma razão científica. O problema psico-patológico suscitado pelos grandes assassinos, frequentemente lúcidos, é um dos mais difíceis que se pode antepor aos médicos. Cumpre reconhecer que a psiquiatria, colocada na extrema vanguarda das ciências biológicas, é ainda insuficientemente objetiva na sua técnica e nas suas interpretações. Entretanto, ninguém ousaria julgar um acusado suspeito de alienação mental, sem antes ouvir um psiquiátra".

Abordando o problema dos psicopatas que vivem em liberdade, Claude, no Congresso de Medicina Legal de 1933, explicou: 
"Se o criminoso não pode ser considerado como um sêr apresentando em si defeitos psico-morais constitucionais, que o levariam, fatalmente, a reações antissociais, há todavia - é preciso reconhecer - individualidades mais ou menos híbridas, a um tempo criminoso e sêres atípicos, denominados loucos morais, isto é, degenerados, portadores de perversões instintivas particularmente acentuadas e nocivas.

"Assim é que, os criminosos recidivistas, sôbre os quais penas anteriores não tiveram efeito regenerador, são tidos como anormais, portadores de taras hereditárias, se bem que uma doença infecciosa possa, em certos e determinados casos, como soi acontecer com a encefalite epidêmica, sobretudo quando ocorrida na infância, provocar lesões corporais mais ou menos intensas, determinando profundas modificações da personalidade, sobretudo na esfera das faculdades morais, como demonstram inúmeras observações registradas em todos os países.

"O número dêsses indivíduos, sôbre os quais as penas não têm efeito regenerador, é realmente assustador, o que comprova também, ao lado dos outros índices médico-psicológicos, sua extrema periculosidade.

Pacheco e Silva afirma e esclarece:

“A moderna psiquiatria criminal já não se pode mais limitar, uma vez verificada a existência de perturbações psíquicas, a classificar o agente num determinado grupo nosográfico. 0 perito fica também na contingência de estudar a personalidade do delinquente sob o tríplice aspecto bio-social, de forma a poder chegar a resultados precisos, não só no que respeita às condições presentes, como ainda para reunir elementos que autorizem prever reações 
antissociais em futuro próximo ou remoto, conforme o caso e as circunstâncias. Acresce ainda o fato de que a avaliação da periculosidade à luz da psiquiatria atual, não pode mais subordinar-se a um critério uniforme. Não é humano, nem atende aos intereses da defesa social, a adoção, por exemplo, de idênticas medidas de segurança a um psicopata constitucional e um enfermo mental ou a um paciente cujo ato delituoso tenha sido cometido no decurso de uma psicose aguda.

"No caso de uma personalidade psicopática, por exemplo, as medidas de segurança, muito embora o paciente não acuse, aparentemente, desordens psíquicas e busque demonstrar os melhores propósitos de emenda e regeneração, devem ser muito mais severas do que as aplicadas a um alienado que haja delinquido movido por idéias delirantes, que se tenham desvanecido por completo, após um tratamento adequado.

"Da mesma forma, conservar anos a fio num asilo de segurança um indivíduo de constituição normal, que no decurso de um estado confusional consequente a uma doença infecciosa, praticou, inconscientemente, um ato criminoso, mas que posteriormente se restabeleceu inteiramente, não oferecendo a menor periculosidade, quer-nos parecer um ato iníquo.

"Há também a considerar os progressos da terapêutica psiquiátrica, que vieram modificar por completo o diagnóstico de muitas psicopatias, antigamente tidas como inexoráveis e que hoje são perfeitamente curáveis.

"Se a justiça admite e reconhece o restabelecimento de um paralítico geral após a malarioterapia, bem como prevê a possibilidade de um esquizofrêni- 
co, após a insulina ou a convulsoterapia, apresentar uma remissão tão completa, que autorize a suspensão da interdição, para que o indivíduo volva a usufruir os seus direitos civis, razão não há para adotar idêntico critério no tocante à responsabilidade $\mathrm{e}$ à periculosidade criminal.

"Vê-se assim que as medidas de segurança não podem obedecer a um critério estritamente jurídico, porquanto o grau de periculosidade varia de acôrdo com a constituição, a moléstia mental de que é ou foi portador determinado indivíduo e de um sem número de outros fatôres, que exigem o estudo dos casos concretos.

"Não se pode, outrossim, ao se considerar a temibilidade de um psicopata, medir-se o grau de periculosidade tomando-se por base a quantidade de crime, para colocar-se em pé de igualdade o crime perfeito e o crime imperfeito.

"Lafora define bem essa questão, quando afirma: "Um irresponsável que tenha cometido um primeiro delito leve, pode ser mais perigoso que outro irresponsável que incorreu acidentalmente em um delito grave e, sem embargo, as medidas de segurança são maiores para aquêle que é menos perigoso, mas, que cometeu delito mais grave que o outro".

Pacheco e Silva conclui: "Os fatos apontados são assaz evidentes para mostrar quanto é difícil a perícia da periculosidade e o cuidado e a prudência que as mesmas exigem".

M. Ruy Funes acentua com muita razão:

"É certo que a culpabilidade é um problema jurídico, não um problema psiquiátrico. Aos tribunais compete declará-la, mas os antecedentes psiquiátri- 
cos que a imputabilidade arrasta consigo são da àlçada exclusiva do perito. A solução única é colocarse, ao lado dos magistrados oficiais e permanentes, peritos médicos oficiais, alheios às sugestões das partes, que atuem objetivamente, e que, em todos os casos de criminalidade, emitam obrigatòriamente 0 seu parecer. 0 exame médico de todos os delinquentes é uma necessidade da justiça e uma necessidade social".

Quanto à disparidade na aplicação das medidas de segurança, em face à prática de delitos leves por parte de criminosos primários, muitas vezes temíveis, a solução seria, para maior garantia da paz social, a aplicação de penas indeterminadas, já em vigor em alguns países. Condenado o indivíduo, êle ficaria num período de observação e de estudos relativo à sua índole moral, decorrente de seu estado bio-psíquico, por onde pudesse se aquilatar de seu verdadeiro grau de periculosidade, funcionando a pena como um verdadeiro processo de readaptação do delinquente ao organismo coletivo, pois esta deve ser sua verdadeira função. Os criminosos degenerados ou inaptados à ordem social, ficariam reclusos, porque pessoas que se portam como feras, não merecem liberdade. Não seria o crime que deveria indicar o grau da pena, mas a conduta do condenado nas penitenciárias, sua maior ou menor possibilidade de regeneração. Deixamos de nos alongar em considerações outras a propósito dêste assunto, afim de não nos desviarmos das linhas fundamentais que traçamos, neste modesto e despretencioso estudo.

Mas a tese é de palpitante interesse para os amantes do Direito Penal, pois os juristas devem se preocupar com todos os problemas que possam interessar à sociedade, aglomerado humano em que vivemos, lutamos e sofremos, visando nosso constante aperfeiçoamento moral e cultural, trabalhando pelo bem comum, porque êste deve ser o legítimo escôpo de todo homem civilizado.

0 indivíduo não deve pensar apenas em si mesmo, nem 
olhar única e egoisticamente para o círculo estreito da família, embora seja o zêlo por esta instituição divina nosso primeiro dever. Quem não sabe amar aos seus, não tem qualidades morais suficientes para amar a sociedade em que vive. Mas cumpre-nos desenvolver atividades outras em proveito da sociedade, da pátria e, se possível, do gênero humano, pois somos cidadãos do Universo.

Os angustiantes problemas do mundo, que também são nossos, devem nos interessar. Assim, lutemos em prol do bom combate, sendo elementos coadjuvadores da evolução, soldados da luz, que espancam as trevas do crime e da ignorância.

$\mathrm{E}$ nós, particularmente, que nos armamos "cavaleiros do direito", dediquemos nossos melhores esforços ao seu estudo e à sua observância, à análise inteligente dos problemas juridico-sociais, porque a justiça é o alimento espiritual tão necessário quanto a liberdade, como expressões da civilização humana, conquistadas até com o adubo generoso do sangue de mártires e de herois, e através do esfôrço silencioso dos sábios, que cimentaram na terra os ideais superiores, os quais, em última análise, provêm dos céus! 